\title{
空間中を湾曲したはり構造物の弾塑性問題のための伝達マトリックス法
}

\author{
黒田 翔一 ${ }^{* 1}$ ，荒井 正行*2，伊藤 潔洋*2
}

\section{Transfer matrix method for elastic-plastic problem of space-curved beam structure}

\author{
Sho-ichi KURODA ${ }^{* 1}$, Masayuki ARAI ${ }^{* 2}$ and Kiyohiro ITO*2 \\ ${ }^{* 1}$ Department of Mechanical Engineering, Graduate School of Engineering, Tokyo University of Science \\ 6-3-1 Niijyuku, Katsushika-ku, Tokyo 125-8585, Japan \\ ${ }^{* 2}$ Department of Mechanical Engineering, Faculty of Engineering, Tokyo University of Science \\ 6-3-1 Niijyuku, Katsushika-ku, Tokyo 125-8585, Japan
}

Received: 23 January 2019; Revised: 23 March 2019; Accepted: 21 May 2019

\begin{abstract}
Problems of space-curved beam structures have been extensively studied by many researchers. Stress analyses for the structural problems are conducted based on a finite element method, boundary element method, or frame structure method. In these methods, a stiffness equation, which is the connection between nodal displacement and force, is solved. The size of a stiffness matrix involved in the stiffness equation increases according to the number of nodes in the analysis model. In this study, the transfer matrix method (TMM) is considered as another analysis method to overcome such a difficulty. In principle, the TMM is based on calculating how the external force or displacement is transmitted to the structure using a state vector that involves both nodal displacement and force. With the use of the state vector, fewer fundamental equations are needed to obtain stress and displacement. However, application of the TMM has been limited to vibration problems. In this study, an incremental form for the TMM is formulated to apply the TMM to the elastic-plastic problem of space-curved beam structures, and the simple problem of a curved beam fixed at a ridged wall is solved to verify the TMM formulation.
\end{abstract}

Keywords : Beam structure, Transfer matrix method, Elastic-plastic problem

\section{1. 緒言}

はりから構成される構造体（以下，はり構造体と呼ぶ）は周知のように様々な分野でみられる．例えば，機械・ 構造物分野では自動車の車体，化学プラントなどのインフラ設備における配管，橋など，生物分野では表皮細胞 における微小管などが挙げられる（例えば，Provasi and Martins, 2014, Liu and Lu, 2016, Hannezo et al., 2012）。この ような構造体に生じる応力状態を知るために，一般的には有限要素法（Finite Element Method: FEM），境界要素法

(Boundary Element Method: BEM)，骨組構造解析法（Frame Structure Method: FSM）（Przemieniecki, 1985）が用い られる。 FEM では解析対象となる体積領域が要素分割される。要素は節点で構成されており，各節点に付随した 節点変位と節点力から剛性マトリックスが組み立てられる。このため，剛性マトリックスの大きさは要素数に依 存する.さらに計算時間も増加することになる. BEMにおいては，解析対象における表面領域のみが要素分割さ れる.ただし，弾塑性解析に際してはFEM と同様に体積領域も要素分割しなければならない. FSMでは解析対 象がはり要素により分割される。そして，はり要素の節点に付随した節点変位と節点力から剛性マトリックスが

\footnotetext{
No.19-00026 [DOI:10.1299/transjsme.19-00026], J-STAGE Advance Publication date : 28 May, 2019

*1 学生員, 東京理科大学大学院 工学研究科 機械工学専攻（率125-8585 東京都葛飾区新宿 6-3-1)

*2 正員, 東京理科大学 工学部 機械工学科

E-mail of corresponding author: marai@rs.tus.ac.jp
} 
組み立てられる. FSM では FEM や BEM と異なりひとつの要素に付随した節点数が少ないため, 剛性マトリッ クスの大きさはこれらに比べて大幅に低減されることになる.

FSM よりも剛性マトリックスの大きさをさらに低減させるために伝達マトリックス法（Transfer Matrix Method: TMM）が開発されている（Pestel and Leckie, 1963）。同手法は解析対象がはり要素により分割される点ではFSM と同様であるが，はり要素の節点 (本研究では端点と呼ぶ) に付随した節点変位と節点力がひとつのベクトル (以 下，状態量ベクトルと呼ぶ）にまとめられる，そして，隣接したはり要素の端点にこの状態量べクトルをつぎつ ぎに伝達させていくことで数值解析を行う。このため, 要素数が増加しても解析に必要となるマトリックスの大 きさは変化しない，このことから，同法はレダクション法（低減法）とも呼ばれている，これまでに TMM は主 に振動解析のために適用されており, この分野において多くの専門書, 学術論文が発表されている（例えば, Geradin and Chen, 1995, Chen et al., 2016, Meng et al., 2013, Zhong et al., 2018, Dastjerdi and Abbasi, 2019)．これに対し て, FEM の急速な発展と普及により TMM が構造解析分野にはほとんど適用されてこなかった.

本研究では，剛性マトリックスの大きさと計算コストの節約が期待できる TMM に注目し，同法に対して回転 マトリックスを導入することで空間内を自由に湾曲するはり構造体を解析できるようにする.さらに弾塑性問題 を解析できるよう TMM の基礎理論を拡張することを目的とする. 本手法の有効性を確認するため, ふたつの直 線はりとひとつの曲がりはりからなるはり構造体を対象に弾塑性解析を実施し, 有限要素解析による解析結果と 比較する.

\section{2. 伝達マトリックス法}

\section{$2 \cdot 1$ 基礎理論}

図 1 に三次元空間中を湾曲するはり構造体を示す，この構造体においてはその一部が剛体壁に固定され，任意 の中間での端点が移動支持, 回転支持されている. さらに外力として, 集中力 $\vec{P}_{i}\left(i=1,2, \ldots, N_{p}\right)$, 曲げモーメン ト，ねじりトルク $\vec{T}_{i}\left(i=1,2, \ldots, N_{T}\right)$ が作用しているものとする.
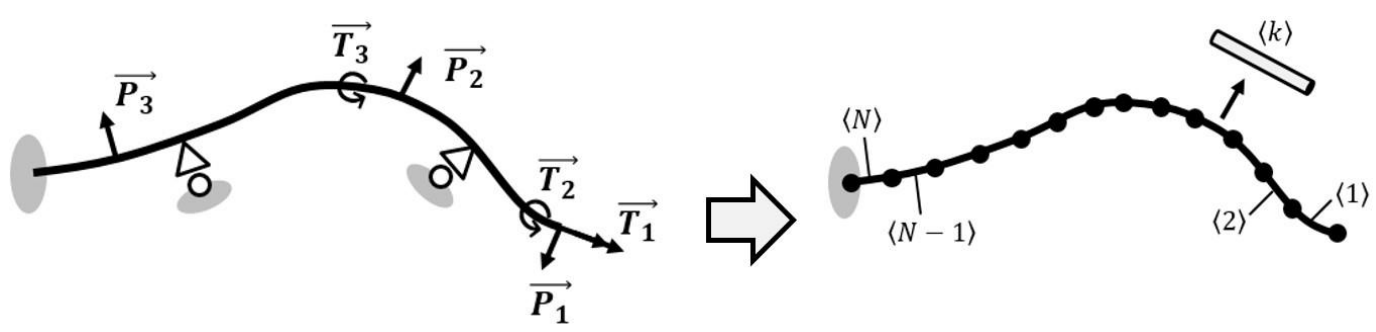

Fig. 1 Beam structure, which is subjected to concentration loads and is constrained at intermediate nodes, and the model divided by beam elements.

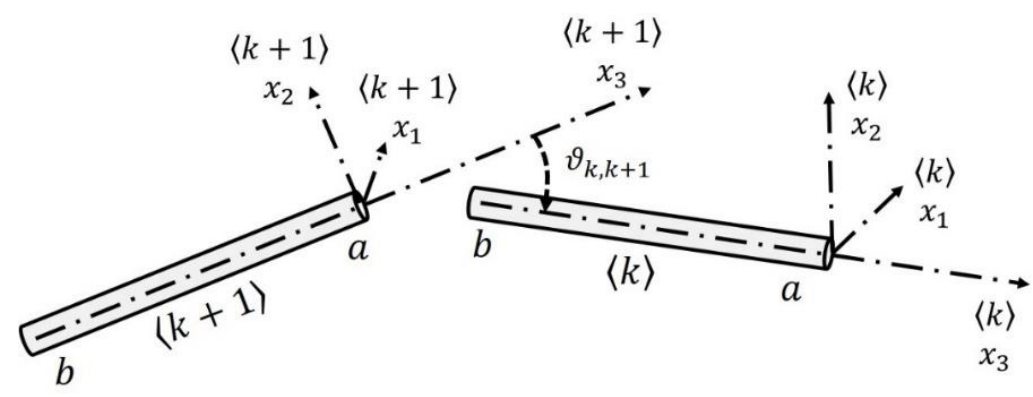

Fig. 2 Configuration of two beam elements $\langle k\rangle$ and $\langle k+1\rangle$. 
このはり構造体を図 1 に示すように任意長さの $N$ 個のはり要素により分割する. 分割後, それぞれの要素に対 して要素番号 $\langle k\rangle(k=1, \ldots, N)$ を割り当てる.つぎに図 2 に示すように要素番号 $\langle k\rangle$ と〈k+1〉のふたつの要素に注

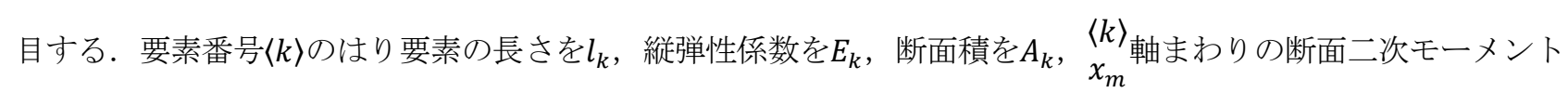
を $I_{k m}(m=1,2)$, 断面二次極モーメントを $I_{p k}$ とする. 本研究では, はり要素の断面が円形状であるものと仮定す る.このはり要素の右端を $a$, 左端を $b$ とし, 要素の軸線に沿って $\underset{x_{3}}{\langle k\rangle}$ を, この軸に直交するように $\left(\begin{array}{c}\langle k\rangle\langle k\rangle \\ x_{1} x_{2}^{\prime}\end{array}\right)$ を局

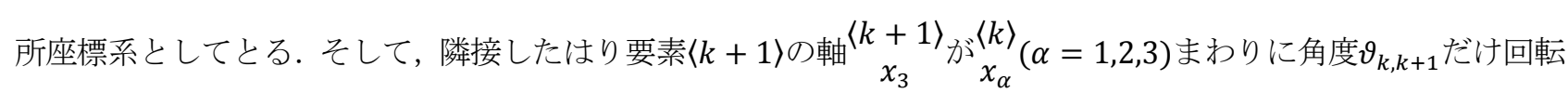
しているものと寸る. このとき, 要素番号〈k〉のはり要素に対して以下の関係式が成り立つ.

$$
\stackrel{\langle k\rangle}{\mathbb{Z}_{b}}=\begin{aligned}
& \langle k\rangle\langle k\rangle \\
& \mathcal{F}_{e} \mathbb{Z}_{a}
\end{aligned}
$$

ここで,

$$
\langle k\rangle=\left\{\begin{array}{l}
\vec{\delta}_{a} \\
\vec{P}_{a} \\
\vec{\varphi}_{a} \\
\vec{T}_{a}
\end{array}\right\}_{k}, \quad\langle k\rangle=\left\{\begin{array}{l}
\vec{\delta}_{b} \\
\vec{P}_{b} \\
\vec{\varphi}_{b} \\
\vec{T}_{b}
\end{array}\right\}_{k}
$$

であり, 式(2)は状態ベクトルと呼ばれる.ここで, $\vec{\delta}_{a}$ ならびに $\vec{\delta}_{b}$ ははり要素の右端 $a$, 左端 $b$ に対する変位ベクト ルであり，局所座標系におけるそれぞれの軸に沿って，

$$
\vec{\delta}_{a}=\left\{\begin{array}{l}
\delta_{a 1} \\
\delta_{a 2} \\
\delta_{a 3}
\end{array}\right\}, \quad \vec{\delta}_{b}=\left\{\begin{array}{c}
\delta_{b 1} \\
\delta_{b 2} \\
\delta_{b 3}
\end{array}\right\}
$$

である．また， $\vec{P}_{a}$ ならびに $\vec{P}_{b}$ は集中力を成分にもつベクトルであり，

$$
\vec{P}_{a}=\left\{\begin{array}{l}
P_{a 1} \\
P_{a 2} \\
P_{a 3}
\end{array}\right\}, \quad \vec{P}_{b}=\left\{\begin{array}{l}
P_{b 1} \\
P_{b 2} \\
P_{b 3}
\end{array}\right\}
$$

である. 同様に $\vec{\varphi}_{a}$ ならびに $\vec{\varphi}_{b}$ はねじり角あるいはたわみ角を成分にもつべクトル， $\vec{T}_{a}$ ならび $\vec{T}_{b}$ はねじりトルクあ るいは曲げモーメントを成分にもつベクトルであり,

$$
\vec{\varphi}_{a}=\left\{\begin{array}{l}
\varphi_{a 1} \\
\varphi_{a 2} \\
\varphi_{a 3}
\end{array}\right\}, \quad \vec{\varphi}_{b}=\left\{\begin{array}{c}
\varphi_{b 1} \\
\varphi_{b 2} \\
\varphi_{b 3}
\end{array}\right\}, \quad \vec{T}_{a}=\left\{\begin{array}{l}
T_{a 1} \\
T_{a 2} \\
T_{a 3}
\end{array}\right\}, \quad \vec{T}_{b}=\left\{\begin{array}{c}
T_{b 1} \\
T_{b 2} \\
T_{b 3}
\end{array}\right\}
$$

ここで, 集中力, 曲げモーメント, ねじりトルク, 変位, たわみ角, ねじり角の方向を付録 $\mathrm{A}$ に示す. また, $\begin{gathered}\langle k\rangle \\ \mathcal{F}_{e}\end{gathered}$ は”弾性伝達マトリックス”と呼ばれ，その成分を付録 B に示寸。 
つぎにはり要素 $\langle k+1\rangle$ の右端 $a$ に対する状態ベクトル $\begin{gathered}\langle k+1\rangle \\ \mathbb{Z}\end{gathered} \underset{a}{ }$ は， はり要素 $\langle k\rangle$ の左端 $b$ 対する状態ベクトル

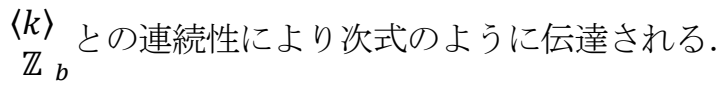

$$
\underset{\mathbb{Z} \quad a}{\langle k+1\rangle}=\mathbb{R}\left(\vartheta_{k, k+1}\right) \stackrel{\langle k\rangle}{\mathbb{Z}_{b}}
$$

ここで, $\mathbb{R}\left(\vartheta_{k, k+1}\right)$ は回転マトリックス

$$
\mathbb{R}\left(\vartheta_{k, k+1}\right)=\left[\begin{array}{cccc}
\mathbb{R}^{(\alpha)}\left(\vartheta_{k, k+1}\right) & 0 & 0 & 0 \\
0 & \mathbb{R}^{(\alpha)}\left(\vartheta_{k, k+1}\right) & 0 & 0 \\
0 & 0 & \mathbb{R}^{(\alpha)}\left(\vartheta_{k, k+1}\right) & 0 \\
0 & 0 & 0 & \mathbb{R}^{(\alpha)}\left(\vartheta_{k, k+1}\right)
\end{array}\right]
$$

であり, $\mathbb{R}^{(\alpha)}\left(\vartheta_{k, k+1}\right)(\alpha=1,2,3)$ は以下のように与えられる. はじめに, $x_{1}$ 軸まわりの回転マトリックスは,

$$
\mathbb{R}^{(1)}\left(\vartheta_{k, k+1}\right)=\left[\begin{array}{ccc}
1 & 0 & 0 \\
0 & \cos \vartheta_{k, k+1} & \sin \vartheta_{k, k+1} \\
0 & -\sin \vartheta_{k, k+1} & \cos \vartheta_{k, k+1}
\end{array}\right]
$$

つぎに $x_{2}$ 軸まわりの回転マトリックスは,

$$
\mathbb{R}^{(2)}\left(\vartheta_{k, k+1}\right)=\left[\begin{array}{ccc}
\cos \vartheta_{k, k+1} & 0 & -\sin \vartheta_{k, k+1} \\
0 & 1 & 0 \\
\sin \vartheta_{k, k+1} & 0 & \cos \vartheta_{k, k+1}
\end{array}\right]
$$

最後に $x_{3}$ 軸まわりの回転マトリックスは,

$$
\mathbb{R}^{(3)}\left(\vartheta_{k, k+1}\right)=\left[\begin{array}{ccc}
\cos \vartheta_{k, k+1} & \sin \vartheta_{k, k+1} & 0 \\
-\sin \vartheta_{k, k+1} & \cos \vartheta_{k, k+1} & 0 \\
0 & 0 & 1
\end{array}\right]
$$

\section{である。}

ここではり要素 $\langle 1\rangle$ かはり要素 $\langle M\rangle$ までの区間において支持部や外部から集中力，曲げモーメント，ねじりト

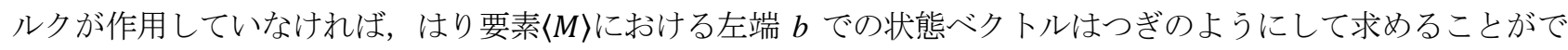
きる. はじめに，はり要素〈1〉において，左端から右端に向けてつぎの関係式により状態べクトルが伝達される.

$$
\begin{aligned}
& \langle 1\rangle=\langle 1\rangle\langle 1\rangle \\
& \mathbb{Z}_{b}=\mathcal{F}_{e} \mathbb{Z}_{a}
\end{aligned}
$$

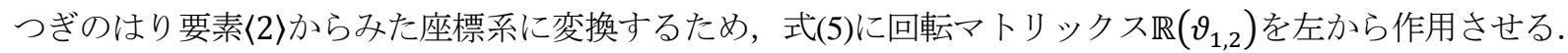

$$
\stackrel{\langle 2\rangle}{\mathbb{Z}_{a}}=\mathbb{R}\left(\vartheta_{1,2}\right)_{\mathbb{Z}_{b}}^{\langle 1\rangle}=\mathbb{R}\left(\vartheta_{1,2}\right)_{\mathcal{F}_{e} \mathbb{Z}_{a}}^{\langle 1\rangle\langle 1\rangle}
$$


一方，はり要素〈2〉においては式(7)により左端から右端に向けて状態ベクトルが伝達される.

$\stackrel{\langle 2\rangle}{\mathbb{Z}_{b}}=\stackrel{\langle 2\rangle\langle 2\rangle}{\mathcal{F}_{e} \mathbb{Z}}$

よって，式(7)に式(6)を代入して，

$\underset{\mathbb{Z}_{b}}{\langle 2\rangle}={ }_{\mathcal{F}_{e}}^{\langle 2\rangle} \mathbb{R}\left(\vartheta_{1,2}\right) \stackrel{\langle 1\rangle\langle 1\rangle}{\mathcal{F}_{e} \mathbb{Z}_{a}}$

再びつぎのはり要素 $(3)$ かみた座標系に変換するために回転マトリックス $\mathbb{R}\left(\vartheta_{2,3}\right)$ を左から作用させる. すると,

$$
\stackrel{\langle 3\rangle}{\mathbb{Z}_{a}}=\mathbb{R}\left(\vartheta_{2,3}\right)_{\mathbb{Z}_{b}}^{\langle 2\rangle}=\mathbb{R}\left(\vartheta_{2,3}\right)_{\mathcal{F}_{e}}^{\langle 2\rangle} \mathbb{R}\left(\vartheta_{1,2}\right)_{\mathcal{F}_{e} \mathbb{Z}_{a}}^{\langle 1\rangle\langle 1\rangle}
$$

この操作をつぎつぎに繰り返し,

$\underset{\mathbb{Z}_{b}}{\langle 2\rangle}={ }_{\mathcal{F}_{e}}^{\langle 2\rangle} \mathbb{R}\left(\vartheta_{1,2}\right)_{\mathcal{F}_{e}}^{\langle 1\rangle\langle 1\rangle}$

${\underset{\mathbb{Z}}{b}}_{b}^{\langle 3\rangle}={ }_{\mathcal{F}_{e}}^{\langle 3\rangle} \mathbb{R}\left(\vartheta_{2,3}\right)_{\mathcal{F}_{e}}^{\langle 2\rangle} \mathbb{R}\left(\vartheta_{1,2}\right)_{\mathcal{F}_{e} \mathbb{Z}_{a}}^{\langle 1\rangle\langle 1\rangle}$

${\underset{\mathbb{Z}}{b}}_{b}^{\langle 4\rangle}={ }_{\mathcal{F}_{e}}^{\langle 4\rangle_{e}} \mathbb{R}\left(\vartheta_{3,4}\right)_{\mathcal{F}_{e}}^{\langle 3\rangle} \mathbb{R}\left(\vartheta_{2,3}\right){ }_{\mathcal{F}_{e}}^{\langle 2\rangle} \mathbb{R}\left(\vartheta_{1,2}\right)_{\mathcal{F}_{e} \mathbb{Z}_{a}}^{\langle 1\rangle\langle 1\rangle}$

$\underset{\mathbb{Z}_{b}}{\langle M\rangle}=\stackrel{\langle M\rangle}{\mathcal{F}_{e}} \prod_{k=2}^{M} \mathbb{R}\left(\vartheta_{k-1, k}\right)^{\langle k-1\rangle} \begin{gathered}\langle k \\ \mathcal{F}_{e}\end{gathered} \stackrel{\mathbb{Z}}{a}^{\langle 1\rangle}$

を得る. 式(9)はまたつぎのように行列表示できる.

$$
\stackrel{\langle M\rangle}{\mathbb{Z}_{b}}=\mathfrak{\Im}_{e} \cdot \stackrel{\langle 1\rangle}{\mathbb{Z}_{a}}
$$

ここで, $\boldsymbol{J}_{e}$ ははり要素〈1)からはり要素 $\langle M\rangle$ までをまとめた弾性伝達マトリックスであり,

$$
\mathfrak{I}_{e}=\stackrel{\langle M\rangle}{\mathcal{F}_{e}} \prod_{k=2}^{M} \mathbb{R}\left(\vartheta_{k-1, k}\right) \begin{gathered}
\langle k-1\rangle \\
\mathcal{F}_{e}
\end{gathered}
$$

である.

つぎにはり要素 $\langle M+1\rangle$ の右端 $a$ に拘束条件として，支持部あるいは外部から集中力 $\vec{P}_{e x}$ ，曲げモーメントある いはねじりトルク $\vec{T}_{e x}$ が与えられているものとすれば, 


$$
\underset{\left.\mathbb{Z} \quad{ }_{a}+1\right\rangle}{\langle M}=\mathbb{R}\left(\vartheta_{M, M+1}\right)_{\mathbb{Z}_{b}}^{\langle M\rangle}+\underset{\mathbb{Z}}{\langle\text { ex }}
$$

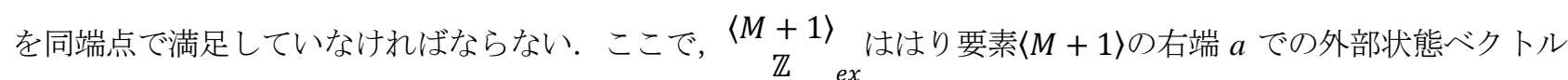
であり，

$$
\langle M+1\rangle \text { ex }=\left\{\begin{array}{c}
0 \\
\vec{P}_{e x} \\
0 \\
\vec{T}_{e x}
\end{array}\right\}_{M+1}
$$

これに加えて支持部での変位，たわみ角あるいはねじり角は，つぎの条件式

$$
\left\{\begin{array}{c}
\vec{\delta}_{a} \\
0 \\
\vec{\varphi}_{a} \\
0
\end{array}\right\}_{M+1}=\mathbb{R}\left(\vartheta_{M, M+1}\right)_{\mathcal{F}_{e}}^{\langle M\rangle}\left\{\begin{array}{c}
\vec{\delta}_{b} \\
0 \\
\vec{\varphi}_{b} \\
0
\end{array}\right\}_{M}
$$

\section{を満足していなければならない.}

つぎにはり要素 $\langle M+1\rangle$ からはり要素 $\langle N\rangle$ までの区間において支持部や集中力，曲げモーメント，ねじりトルク が作用していないものとすれば，はり要素〈N〉における左端 $b$ での状態ベクトルは,

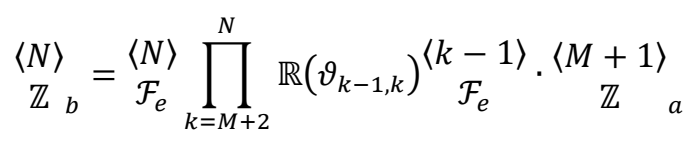

となる.

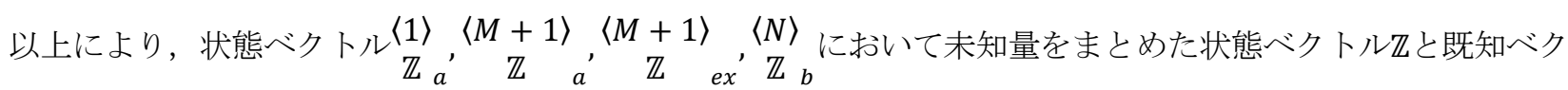
トルそに振り分けるとともに条件式(14)を考慮することでつぎのような行列方程式が得られる.

$$
A \mathbb{Z}=\xi
$$

結局, 方程式(16)を解けばよい。これにより得られた結果を用いて, 例えばはり要素〈K〉の左端 $b$ における断面に 生じる応力成分はつぎのようにして求めることができる. 再びはり要素〈1)から伝達マトリックスと回転マトリッ クスを左側から連続的に作用させていく．するとはり要素〈K〉の左端 $b$ における状態ベクトルは,

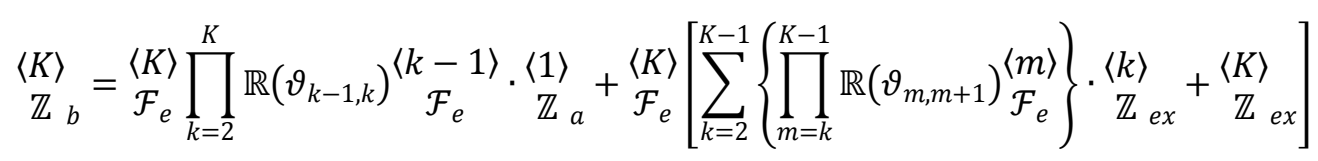

となる.よって, 㸚じりトルク $T_{b 3}$ からせん断応力 $\sigma_{3 \theta}$ は, 


$$
\sigma_{3 \theta}=\frac{T_{b 3}}{I_{p K}}\left(\frac{d_{0}}{2}\right)
$$

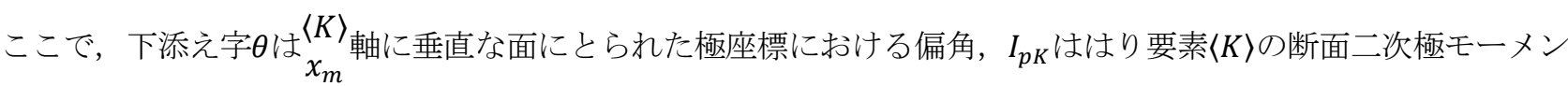
トである.はり要素の外径を $d_{0}$, 内径を $d_{i}$ とすれば,

$$
I_{p K}=\frac{\pi}{32}\left(d_{0}^{4}-d_{i}^{4}\right)
$$

である.つぎに垂直応力は,

$$
\sigma_{33}=\frac{P_{b 3}}{A_{K}}-\frac{T_{b 2}}{I_{K 2}} x_{1}+\frac{T_{b 1}}{I_{K 1}} x_{2}
$$

により評価できる.ここで， $A_{K}$ は断面積であり，

$$
A_{K}=\frac{\pi}{4}\left(d_{0}^{2}-d_{i}^{2}\right)
$$

また， $I_{K 1}$ と $I_{K 2}$ は $x_{1}$ 軸と $x_{2}$ 軸に対するはり要素 $\langle K\rangle の$ 断面二次モーメントである.ただし，断面は一様な円形状で あることから，断面二次モーメントは軸の取り方にはよらない. このため, $I_{K 1}=I_{K 2} \equiv I_{K}$ とおいてもよい.

$$
I_{K}=\frac{\pi}{64}\left(d_{0}^{4}-d_{i}^{4}\right)
$$

\section{$2 \cdot 2$ 弾塑性問題への基礎理論の拡張}

TMM により弾塑性問題を解析できるよう前節に示した基礎理論を拡張する。はり構造体の弾塑性問題におい ては，構造体の一部で局所的に降伏現象が生じ，断面にわたって塑性変形が進行していく．このために本研究で は，最終的な外部状態ベクトルを分割し，分割された外部状態ベクトル増分量に対して弾塑性解析を逐次行って いく. 本節では図 3 に示すはり構造問題を取り上げる. 図ははり要素数 $N$ 個が連結された構造体を示している. 本研究では同構造体を弾完全塑性体と仮定した。

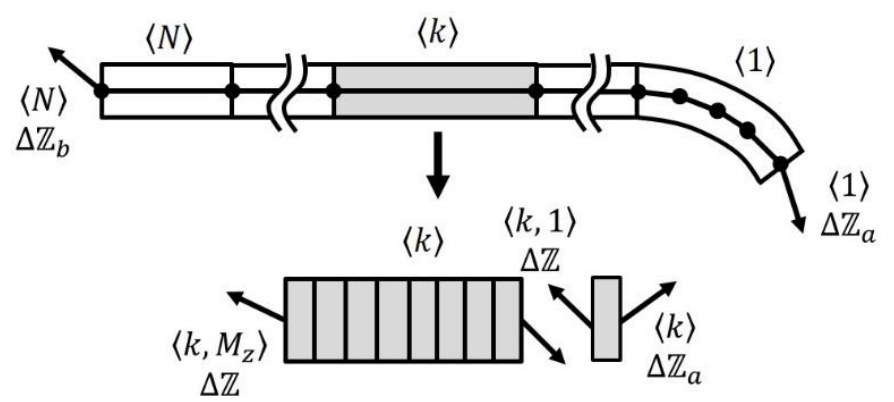

Fig. 3 Elastic-plastic model of the beam structure. 
はじめにはり要素〈1〉の右端 $a$ に外部から作用している状態ベクトル $\underset{\mathbb{Z}}{a}$ をステップ数 $N_{\text {step }}$ で除したつぎの外 部状態ベクトル増分量

$\stackrel{\langle 1\rangle}{\Delta \mathbb{Z}_{a}}=\frac{1}{N_{\text {step }}} \stackrel{\langle 1\rangle}{\mathbb{Z}} \underset{a}{ }$

を導入する. そしてあるステップ数 $n\left(1 \leq n \leq N_{s t e p}\right)$ におけるはり要素 $\langle k\rangle(k=1,2, \ldots, N)$ について考える. はり 構造体のどの位置で降伏するのか判断する必要があるために，この要素をさらに $M_{z}$ 個に分割する. ここでは，こ のように分割された要素を “サブ要素” と呼び，サブ要素番号を $\langle k, m\rangle\left(k=1,2, \ldots, N ; m=1,2, \ldots, M_{z}\right)$ とする. こ れにより, サブ要素番号 $\langle k, 1\rangle$ における右端での状態ベクトル増分量 ${ }_{\Delta \mathbb{Z}_{a}}\left\langle k\right.$ は, 左唄から弾性伝達マトリックス ${ }_{\mathcal{F}_{e}}^{\langle k, 1\rangle}$ を作用することで,

$$
\begin{gathered}
\langle k, 1\rangle \\
\Delta \mathbb{Z}
\end{gathered}=\begin{gathered}
\langle k, 1\rangle\langle k\rangle \\
\mathcal{F}_{e} \quad \Delta \mathbb{Z}_{a}
\end{gathered}
$$

この状態ベクトル増分量式(21)を用いて後述する応力評価を行い，断面上で降伏しているかどうか判断する．降 伏している場合には

$$
\underset{\mathcal{F}_{e}}{\langle k, 1\rangle} \Rightarrow \stackrel{\langle k, 1\rangle}{\mathcal{F}_{p}}
$$

のように置き換える. ここで, 伝達マトリックス $\underset{\mathcal{F}_{p}}{\langle k, 1\rangle}$ を”塑性伝達マトリックス”と呼ぶこととする. このマト リックス成分の詳細については後述する。

つぎにサブ要素番号〈k,2〉の計算を行う.

$$
\begin{array}{cccc}
\langle k, 2\rangle \\
\Delta \mathbb{Z}
\end{array}=\begin{array}{cccc}
\langle k, 2\rangle\langle k, 1\rangle\langle k\rangle \\
\mathcal{F}_{l} & \mathcal{F}_{l} & \Delta \mathbb{Z}_{a}
\end{array}(l=\text { e or } p)
$$

引き続き状態ベクトル増分量式(22)を用いて応力評価を行い，断面上で降伏しているかどうか判断する．この手 順をサブ要素番号 $\left\langle k, M_{z}\right\rangle$ まで繰返していく。この結果,

$$
\begin{gathered}
\left\langle k, M_{Z}\right\rangle \\
\Delta \mathbb{Z}
\end{gathered}=\prod_{i=1}^{M_{Z}}\left\langle\begin{array}{c}
\langle k, i\rangle\langle k\rangle \\
\mathcal{F}_{l} \Delta \mathbb{Z}_{a}
\end{array}(l=\text { e or } p)\right.
$$

を得る.ここで，

$$
\begin{gathered}
\left\langle k, M_{z}\right\rangle \\
\Delta \mathbb{Z}
\end{gathered}=\begin{aligned}
& \langle k\rangle \\
& \Delta \mathbb{Z}_{b}
\end{aligned}
$$

であるから， 


$$
\begin{aligned}
& \langle k\rangle \\
& \Delta \mathbb{Z}_{b}
\end{aligned}=\prod_{i=1}^{M_{z}} \begin{gathered}
\langle k, i\rangle\langle k\rangle \\
\mathcal{F}_{l} \Delta \mathbb{Z}_{a}
\end{gathered}(l=\text { e or } p)
$$

式(24)はまた，

$$
\begin{aligned}
& \langle k\rangle \\
& \Delta \mathbb{Z}_{b}
\end{aligned}=\frac{\langle k\rangle}{\boldsymbol{J}_{\text {ep }}} \cdot\langle k\rangle
$$

のようにも書ける.ここで,

$$
\begin{gathered}
\langle k\rangle \\
\mathfrak{I}_{\text {ep }}
\end{gathered}=\prod_{i=1}^{M_{z}} \begin{gathered}
\langle k, i\rangle \\
\mathcal{F}_{l}
\end{gathered}(l=\text { e or } p)
$$

であり, 本研究では式(26)を”弾塑性伝達マトリックス”と呼ぶ. 以上の操作を繰り返していくことにより, ここ で対象としているはり構造問題に対しては,

$$
\begin{aligned}
& \langle N\rangle=\langle N\rangle \ldots\langle 3\rangle,\langle 2\rangle,\langle 1\rangle,\langle 1\rangle \\
& \Delta \mathbb{Z}_{b}=\mathfrak{I}_{\text {ep }} \cdots \cdot \mathfrak{I}_{\text {ep }} \cdot \mathfrak{I}_{\text {ep }} \cdot \mathfrak{J}_{\text {ep }} \quad \Delta \mathbb{Z}_{a}
\end{aligned}
$$

が得られる.なお，はり構造物の途中に曲がり部がある場合には，式(27)の右辺において弾塑性伝達マトリックス 間に回転マトリックスRを挿入すればよい.

以上の計算をステップ $N_{\text {step }}$ に到達するまで繰り返す.

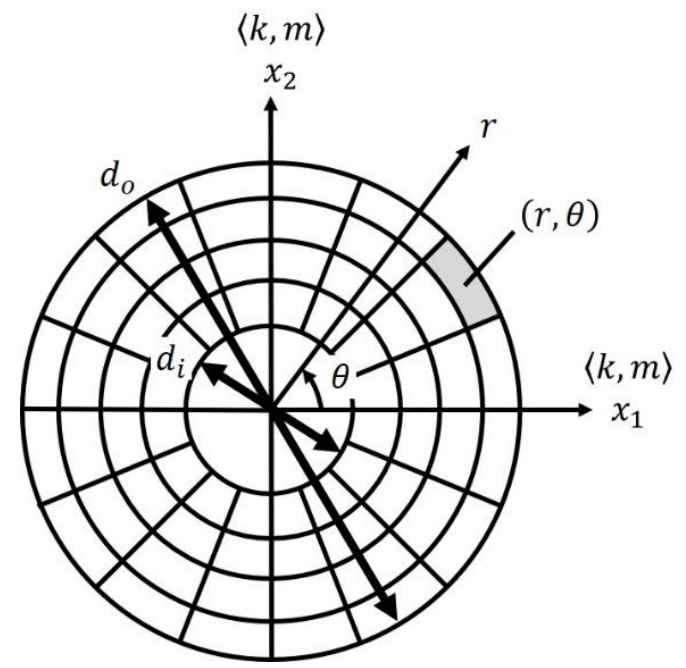

Fig. 4 The cross section divided by $M_{r}$ and $M_{\theta}$ in the sub-element $\langle k, m\rangle$.

サブ要素番号 $\langle k, m\rangle$ における断面での降伏判定はつぎのように行う. まず対象断面を図 4 のように分割する. ここで, 断面の分割数を半径方向に $M_{r}$ 個, 周方向に $M_{\theta}$ 個とする. これにより断面中心から半径方向に $M_{r i}$ 番目 $(i=$ $\left.1, \ldots, M_{r}\right), x_{1}$ 軸から反時計回りに $M_{\theta j}$ 番目 $\left(j=1, \ldots, M_{\theta}\right)$ の座標は, 


$$
\left(r_{i}, \theta_{j}\right)=\left(\frac{d_{i}}{2}+\frac{d_{o}-d_{i}}{2 M_{r}}\left(M_{r i}-\frac{1}{2}\right), \frac{2 \pi}{M_{\theta}}\left(M_{\theta j}-\frac{1}{2}\right)\right)
$$

となる.このようにして分割された断面の領域を “断面要素”と呼ぶこととする. この断面要素に生じている応 力成分の増分量 $\Delta \sigma_{33}(n), \Delta \sigma_{3 \theta}(n)$ は, つぎの状態ベクトル増分量

$$
\begin{gathered}
\langle k, m\rangle \\
\Delta \mathbb{Z}
\end{gathered}=\prod_{i=1}^{m} \begin{gathered}
\langle k, i\rangle\langle k\rangle \\
\mathcal{F}_{l} \Delta \mathbb{Z}_{a}
\end{gathered}(l=\text { e or } p)
$$

から以下のように計算できる.ここで, 各応力成分における $(n)$ はステップ数 $n\left(1 \leq n \leq N_{\text {step }}\right)$ での応力成分の増 分量を意味する.

$$
\left\{\begin{array}{l}
\Delta \sigma_{33}(n)=\frac{\Delta P_{3}}{A_{\langle k, m\rangle}}-\frac{\Delta T_{2} r_{i} \cos \theta_{j}}{2 I_{\langle k, m\rangle 2}}+\frac{\Delta T_{1} r_{i} \sin \theta_{j}}{2 I_{\langle k, m\rangle 1}} \\
\Delta \sigma_{3 \theta}(n)=\frac{\Delta T_{3}}{I_{p\langle k, m\rangle}} r_{i}
\end{array}\right.
$$

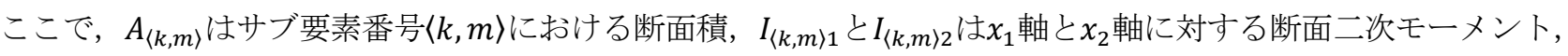
$I_{p\langle k, m\rangle}$ は断面二次極モーメントである. そして, これまでのステップで得られている応力成分の増分量の総和を とる.

$$
\boldsymbol{\sigma}(n+1)=\Delta \boldsymbol{\sigma}(1)+\Delta \boldsymbol{\sigma}(2)+\cdots+\Delta \boldsymbol{\sigma}(n-1)+\Delta \boldsymbol{\sigma}(n) \quad\left(\boldsymbol{\sigma}(n)=\left\{\begin{array}{c}
\sigma_{33}(n) \\
\sigma_{3 \theta}(n)
\end{array}\right\}\right)
$$

そしてこのようにして得られた応力成分から断面要素 $\left(r_{i}, \theta_{j}\right)$ における相当応力 $\sigma_{\text {mises }}$ を以下の式より算出する.

$$
\sigma_{\text {mises }}(n+1)=\sqrt{\sigma_{33}^{2}+3 \sigma_{3 \theta}^{2}}
$$

結局, 式(32)を降伏応力 $\sigma_{y}$ と比較し, 降伏応力より高い断面要素を $n+1$ ステップ開始時の塑性域と判定する. こ の評価を断面上のすべての断面要素に対して行い, 降伏している領域を判定していく.

つぎにサブ要素番号 $\langle k, m\rangle$ における断面に対する図心, 面積, 断面二次モーメント, 断面二次極メーメントにつ いては以下の通りである.はじめに配管の面積 $A_{k}$ は全断面積から塑性域となった面積を除外することで求められ る. これは本構造体を弾完全塑性体と仮定しているため, 塑性域における応力成分の増分量 $\Delta \sigma(n)$ が 0 となるこ とによる.ここでサブ要素番号 $\langle k, m\rangle$ における断面要素 $\left(r_{i}, \theta_{j}\right)$ が塑性域であるとすると, 塑性域となった面積 $A_{p\langle k, m\rangle}\left(r_{i}, \theta_{j}\right)$ は,

$$
A_{p\langle k, m\rangle}\left(r_{i}, \theta_{j}\right)=\frac{\pi}{4 M_{\theta}}\left(\left(d_{i}+\frac{d_{o}-d_{i}}{M_{r}} M_{r i}\right)^{2}-\left(d_{i}+\frac{d_{o}-d_{i}}{M_{r}}\left(M_{r i}-1\right)\right)^{2}\right)
$$

である.このことから，この面積を除外した断面積は， 


$$
A_{\langle k, m\rangle}=\frac{\pi}{4}\left(d_{o}^{2}-d_{i}^{2}\right)-A_{p\langle k, m\rangle}\left(r_{i}, \theta_{j}\right)
$$

となる. 塑性域がさらに他の断面要素に進展した場合にも，ここから塑性域となった断面要素の面積を除外寸れ ばよく,

$$
A_{\langle k, m\rangle}=\frac{\pi}{4}\left(d_{o}^{2}-d_{i}^{2}\right)-\sum_{i, j} A_{p\langle k, m\rangle}\left(r_{i}, \theta_{j}\right)
$$

つぎに塑性域の面積が除外されることにより中立軸，つまり座標軸 $\begin{gathered}\langle k, m\rangle \\ x_{1}\end{gathered}, \begin{gathered}\langle k, m\rangle \\ x_{1}\end{gathered}$ が移動することになる．な お, 以降では簡単のために $\begin{gathered}\langle k, m\rangle \\ x_{1}\end{gathered} \rightarrow x_{1}$ ならびに $\begin{gathered}\langle k, m\rangle \\ x_{2}\end{gathered} \rightarrow x_{2}$ のようにおく. 初期状態の座標軸 $x_{1}, x_{2}$ からの中立 軸の移動距離をそれぞれ $\overline{y_{1}}, \overline{y_{2}}$ とすると，それらは

$$
\begin{gathered}
\overline{y_{1}}=\frac{\int_{A_{\langle k, m\rangle}} x_{2} d A_{\langle k, m\rangle}}{A_{\langle k, m\rangle}}=\frac{-\sum_{i, j} x_{2} A_{p\langle k, m\rangle}\left(r_{i}, \theta_{j}\right)}{\frac{\pi}{4}\left(d_{o}^{2}-d_{i}^{2}\right)-\sum_{i, j} A_{p\langle k, m\rangle}\left(r_{i}, \theta_{j}\right)} \\
\overline{y_{2}}=\frac{\int_{A_{\langle k, m\rangle}} x_{1} d A_{\langle k, m\rangle}}{A_{\langle k, m\rangle}}=\frac{-\sum_{i, j} x_{1} A_{p\langle k, m\rangle}\left(r_{i}, \theta_{j}\right)}{\frac{\pi}{4}\left(d_{o}^{2}-d_{i}^{2}\right)-\sum_{i, j} A_{p\langle k, m\rangle}\left(r_{i}, \theta_{j}\right)}
\end{gathered}
$$

と表すことができる.ここで，

$$
x_{1}=r_{i} \cos \theta_{j}, x_{2}=r_{i} \sin \theta_{j}
$$

さらに座標軸 $x_{1}, x_{2}$ が移動するとそれに伴い断面二次モーメント $I_{\langle k, m\rangle 1}, I_{\langle k, m\rangle 2}$ も変化する. 初期の座標軸 $x_{1}$, $x_{2}$ 周りの塑性域を考慮した断面二次モーメント $I_{p l 1}, I_{p l 2}$ は,

$$
\begin{aligned}
& I_{p l 1}=\int_{A_{\langle k, m\rangle}}\left(x_{2}\right)^{2} d A_{\langle k, m\rangle}=\frac{\pi}{64}\left(d_{o}^{4}-d_{i}^{4}\right)-\sum_{i, j}\left(x_{2}\right)^{2} A_{p\langle k, m\rangle}\left(r_{i}, \theta_{j}\right) \\
& I_{p l 2}=\int_{A_{\langle k, m\rangle}}\left(x_{1}\right)^{2} d A_{\langle k, m\rangle}=\frac{\pi}{64}\left(d_{o}^{4}-d_{i}^{4}\right)-\sum_{i, j}\left(x_{1}\right)^{2} A_{p\langle k, m\rangle}\left(r_{i}, \theta_{j}\right)
\end{aligned}
$$

となり, 移動後の座標軸 $x_{1}, x_{2}$ 周りの断面二次モーメント $I_{\langle k, m\rangle 1}, I_{\langle k, m\rangle 2}$ は中立軸の定理より，

$$
\begin{aligned}
& I_{\langle k, m\rangle 1}=I_{p l 1}+\overline{y_{1}} A_{\langle k, m\rangle} \\
& I_{\langle k, m\rangle 2}=I_{p l 2}+\overline{y_{2}} A_{\langle k, m\rangle}
\end{aligned}
$$

また，断面二次極モーメント $I_{p\langle k, m\rangle}$ も断面積が変わることでつぎのように変化する. 


$$
I_{p\langle k, m\rangle}=\int_{A_{\langle k, m\rangle}} r^{2} d A_{\langle k, m\rangle}=\frac{\pi}{32}\left(d_{o}^{4}-d_{i}^{4}\right)-\sum_{i, j} r_{i}^{2} A_{p\langle k, m\rangle}\left(r_{i}, \theta_{j}\right)
$$

このように弾性伝達マトリックス $\underset{\mathcal{F}_{e}}{\langle k, m\rangle}$ 内の行列成分のうち, $A_{k}, I_{k 1}, I_{k 2}, I_{p k}$ をそれぞれ $A_{\langle k, m\rangle}, I_{\langle k, m\rangle 1}, I_{\langle k, m\rangle 2}$, $I_{p\langle k, m\rangle}$ に置き換えることで塑性伝達マトリックス $\underset{\mathcal{F}_{p}}{\langle k, m\rangle}$ が得られる.

\section{3. 数値解析}

\section{$3 \cdot 1$ 解析モデルと解析条件}

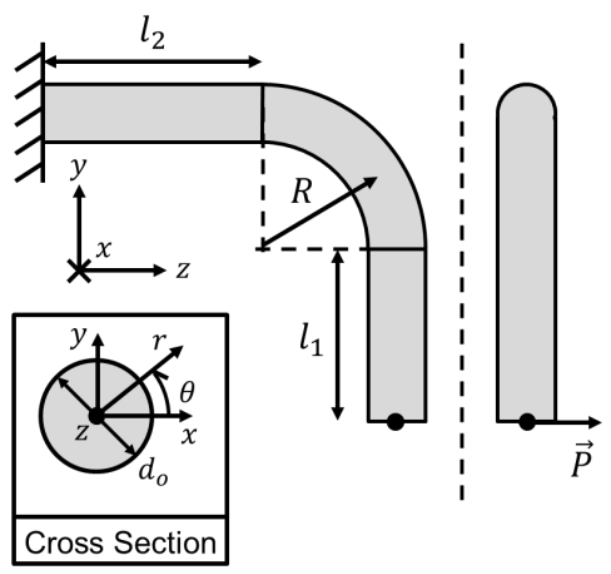

(a) Beam structure model prepared in this study

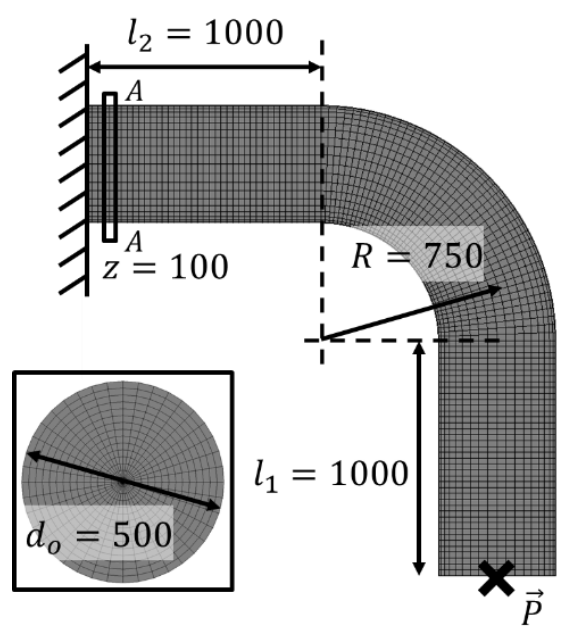

(b) Finite element model

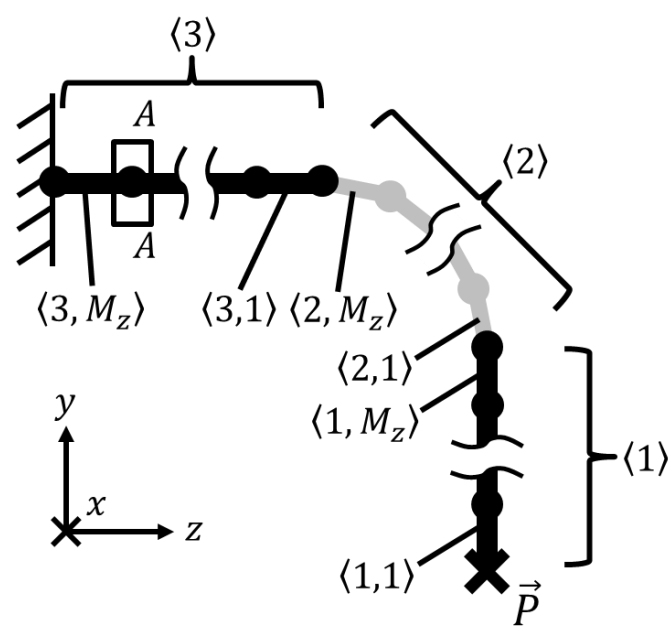

(c) TMM model

Fig. 5 Beam structure which is fixed at the ridged wall and subjected to a concentrated load.

本研究では，第二章に示した基礎理論と解析手法の有効性を検証するために，図 5(a)に示す直線はりと曲がり はりからなるはり構造体を対象に解析を行った。はり構造体の端部は剛体壁に固定されており，他端には集中力 $P$ 作用している. 図 5(b)に有限要素解析モデル, 図 5(c)に TMM モデルをそれぞれ示す. 有限要素解析モデルに 用いた要素は三次元直方体要素であり, 要素数は 75000 である.このとき, ふたつの直線部における要素分割数 は半径方向 $M_{r}=15$, 周方向 $M_{\theta}=40$, 軸方向 $M_{z}=40$ とし, 曲がり部における要素分割数は $M_{r}=15, M_{\theta}=40, M_{z}=45$ 
とした．また，解析的に導出された塑性崩壊荷重值に基づいて最大集中荷重 $P$ を $3000 \mathrm{kN}$ とした。表 1 に解析に 用いた材料定数ならびにはり構造体の形状についてまとめて示す。なお，はり構造体の構成式には弾完全塑性体 を仮定した. そして, 有限要素解析結果との比較を通じて本解析手法の有効性を検証することとした. また, TMM 解析には第二章に示した理論に基づいて作成したプログラムを用いた，なお，局所座標系として図のように直角 座標系 $\left(x_{1}, x_{2}, x_{3}\right)=(x, y, z)$ ならびに極座標系 $(r, \theta, z)$ をおいた。

Table 1 Material constants and size of the beam structure.

\begin{tabular}{c|c|c|c|c|c|c|c}
\hline $\begin{array}{c}\text { Young's modulus } \\
E[\mathrm{GPa}]\end{array}$ & $\begin{array}{c}\text { Poisson's } \\
\text { ratio } \\
\boldsymbol{v}\end{array}$ & $\begin{array}{c}\text { Yield } \\
\text { stress } \\
\boldsymbol{\sigma}_{\boldsymbol{y}}[\mathrm{MPa}]\end{array}$ & $\begin{array}{c}\text { Outer } \\
\text { diameter } \\
\boldsymbol{d}_{\mathbf{0}}[\mathrm{mm}]\end{array}$ & $\begin{array}{c}\text { Inner } \\
\text { diameter } \\
\boldsymbol{d}_{\boldsymbol{i}}[\mathrm{mm}]\end{array}$ & $\begin{array}{c}\text { Beam } \\
\text { length } \\
\boldsymbol{l}_{\mathbf{1}}[\mathrm{mm}]\end{array}$ & $\begin{array}{c}\text { Beam } \\
\text { length } \\
\boldsymbol{l}_{\mathbf{2}}[\mathrm{mm}]\end{array}$ & $\begin{array}{c}\text { Curvature } \\
R[\mathrm{~mm}]\end{array}$ \\
\hline 157.1 & 0.3 & 217 & 500 & 0 & 1000 & 1000 & 750 \\
\hline
\end{tabular}

\section{$3 \cdot 2$ 解析結果}

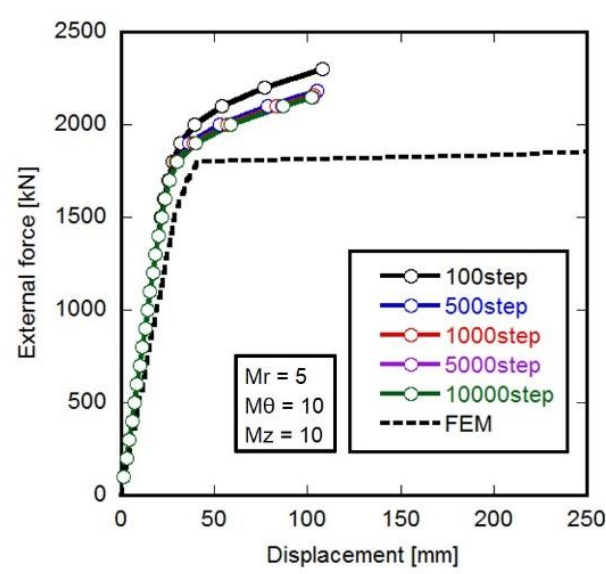

(a)Influence of number of steps

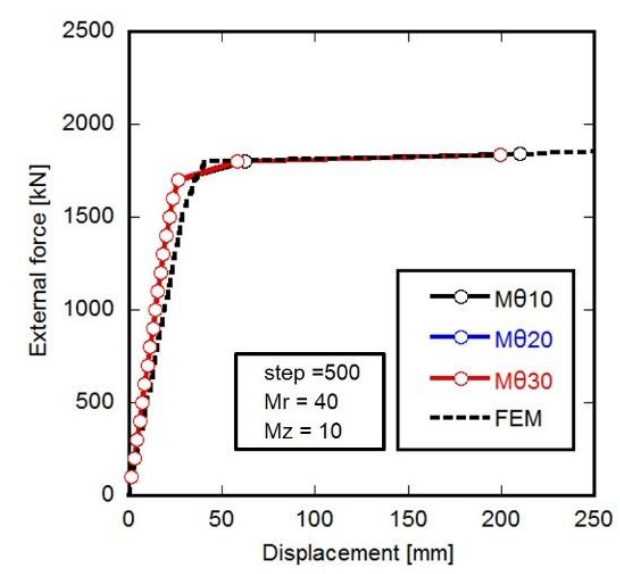

(c) Influence of number of divisions $M_{\theta}$ for circumferential direction

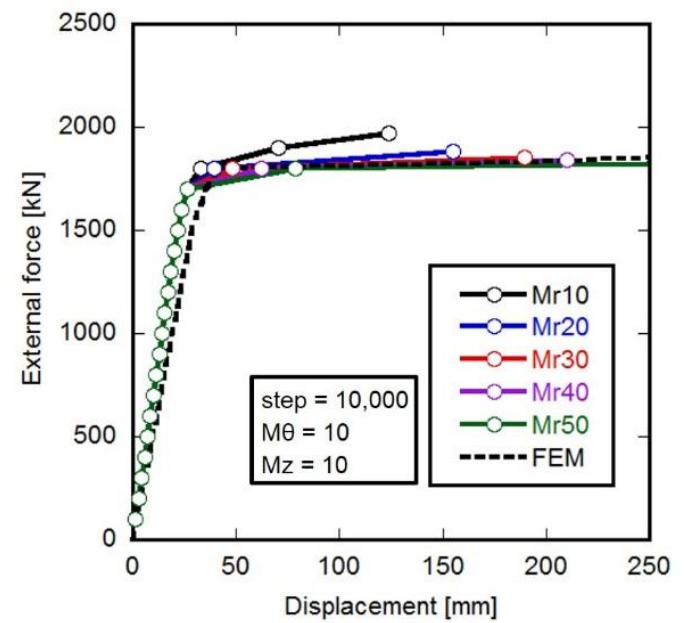

(b)Influence of number of divisions $M_{r}$ for radial direction

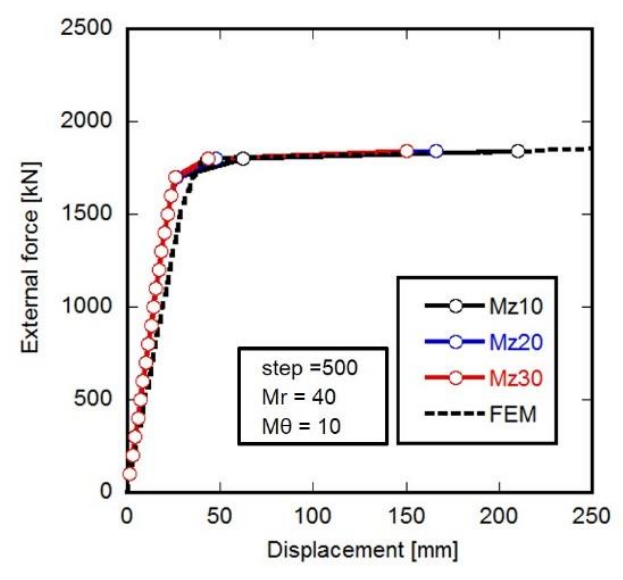

(d)Influence of number of divisons $M_{z}$ for axial direction

Fig. 6 Comparison in external force-displacement diagram between FEM and TMM. Influence of number of incremental steps $\mathrm{N}_{\text {step }}$ and divisions of $M_{r}, M_{\theta}$ and $M_{z}$ on eternal force-displacement diagram was examined to find best division for TMM analysis model. 
図 6 に集中力と作用点での変位（以下，変位と呼ぶ）の関係を示す.図 6(a)にステップ数 $N_{s t e p}$ の違いが集中力 と変位の関係に及ぼす影響を示す．このときのサブ要素数はふたつの直線部，曲がり部ともに $M_{r}=5, \quad M_{\theta}=10$, $M_{Z}=10$ とした．また，図中の○印は TMM による解析結果，破線は FEM による解析結果をそれぞれ示す．図よ り，TMM による解析結果は，ステップ数によらず FEM のそれに比べてやや高い. この違いは，TMM モデルに おける要素分割数が不十分であったことによる．ただし，ステッブ数の違いが集中荷重と変位の関係に及ぼす影 響は小さいことがわかった，このため，以降の TMM 解析ではステップ数 $N_{\text {step }}=500$ に固定することとした．図 6(b)に半径方向の分割数 $M_{r}$ の違いが集中力と変位の関係に及ぼす影響を示す. このときのサブ要素数は直線部, 曲がり部ともに $M_{\theta}=10, M_{z}=10$ とした. 図より, 半径方向の分割数 $M_{r}$ が増加するにつれて TMM による結果は FEM による結果に近づいていくことがわかる. $M_{r}=40$ にて両者はほとんど一致している. このためこれ以降の 解析では半径方向の分割数 $M_{r}=40$ にて固定することとした. 図 $6(\mathrm{c})$ に周方向の分割数 $M_{\theta}$ の違いが集中力と変位 の関係に及ぼす影響を示す.このときのサブ要素数は直線部，曲がり部ともに $M_{z}=10$ とした. 図より周方向の分 割数 $M_{\theta}$ が増加しても TMM による結果は FEM による結果にほとんど一致していることがわかる．これにより周 方向の分割数の違いが解析結果に及ぼす影響は少ないことがわかった. 最後に図 $6(\mathrm{~d})$ に軸方向 $M_{z}$ の違いが集中力 と変位の関係に及ぼす影響を示す.この結果においても軸方向の分割数 $M_{z}$ が増加しても TMMによる結果は FEM による結果とほとんど一致していることがわかる。このことから軸方向の分割数の違いが解析結果に及ぼす影響 は少ないことがわかった。

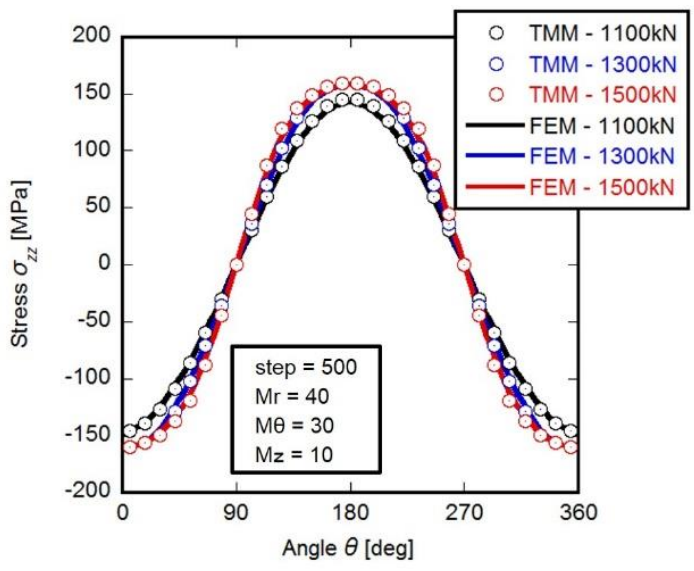

(a) Stress distribution $\sigma_{z z}$

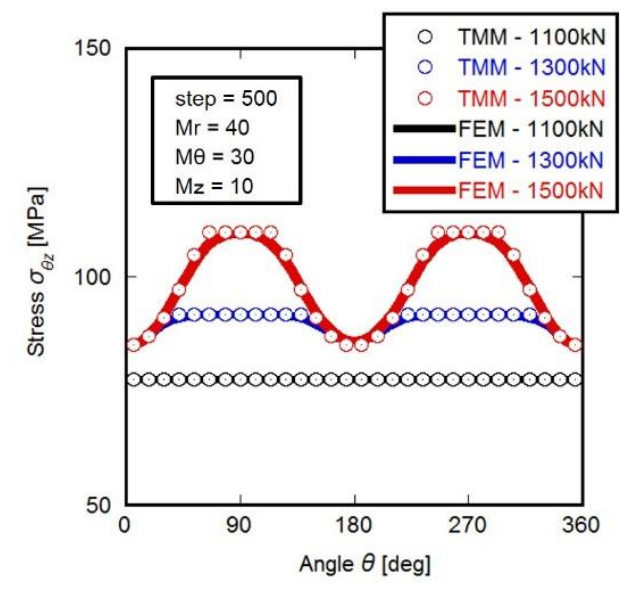

(b) Stress distribution $\sigma_{\theta z}$

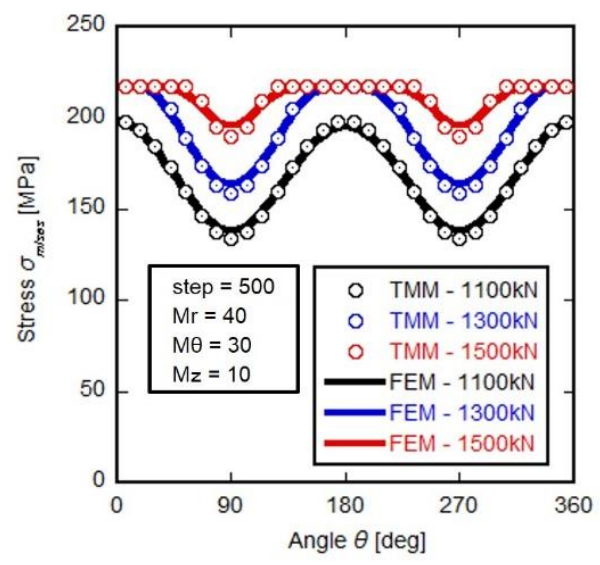

(c) Stress distribution $\sigma_{\text {mises }}$

Fig. 7 Stress distributions $\sigma_{z z}, \sigma_{\theta z}$ and $\sigma_{\text {mises }}$ along angle $\theta$ at A-A section on the surface of beam model. It was confirmed that stress distribution obtained by FEM accords with one estimated by TMM. 
最後に図 7 に図5(b)の A-A 断面における表面での角度 $\theta$ に伴う応力の変化を示寸. ここで, ステップ数 $N_{s t e p}=500$, $M_{r}=40, M_{\theta}=30, M_{z}=10$ とし, 集中力については $P=1100,1300,1500 \mathrm{kN}$ の結果について示している. また, 図中の○印は TMM による解析結果，実線はFEM による結果をそれぞれ示している. 図 7(a)に垂直応力 $\sigma_{z z}$ の変 化を示寸．図より，TMM による解析結果と FEM によるそれは概ねよく一致していることが確認できる．TMM の解析結果に注目すると, 集中力 $P=1100 \mathrm{kN}$ では A-A 断面は降伏しておらず，はり右側面と左側面で垂直応力が 最も高くなる.さらに集中力が $P=1300 \mathrm{kN}$ になるとはり右側面と左側面で降伏が開始する．そして $P=1500 \mathrm{kN}$ に なるとはりの右側面ならびに左側面で降伏が進行している様子が確認できる. 図 7(b)にせん断応力 $\sigma_{\theta z}$ の変化を示 す.この結果においても TMMによる解析結果と FEMによるそれは概ねよく一致している．TMM の解析結果に 注目すると, 集中力 $P=1100 \mathrm{kN}$ では A-A 断面は降伏しておらず，せん断応力が一定となる.さらに集中力が $P=1300 \mathrm{kN}$ になるとはり右側面と左側面が降伏し，せん断応力が増加しないようになる．そして $P=1500 \mathrm{kN}$ にな るとはりの右側面ならびに左側面で降伏が進行し, 最も降伏に達するのが遅いはりの上面と下面にてせん断応力 が最大となる. 最後に図 7(c)に相当応力 $\sigma_{\text {mises }}$ の変化を示す.この結果においても TMM による解析結果と FEM によるそれは概ねよく一致している. TMM の解析結果に注目寸ると, 集中力 $P=1100 \mathrm{kN}$ では A-A 断面は降伏し ておらず，はり右側面と左側面で相当応力が最も高くなる. さらに集中力が $P=1300 \mathrm{kN}$ になると相当応力の最大 值が降伏応力に一致するようになる. そして $P=1500 \mathrm{kN}$ になるとはりの右側面ならびに左側面で降伏が進行して いる様子が確認できる.これらのことから TMMにより適切に弾塑性解析が行われていることが確認された。

以上の直線はりと曲がりはりからなる単純なはり構造体に対する TMM 解析を通じて, 少ない要素分割数にて 高精度に構造解析が行えること, 弾塑性解析においてはサブ要素分割における断面上の半径方向に対して細かく 分割することで精度よく応力分布を評価できることが確認された．なお，FEM ではいずれの解析ケースにおい ても 6.5 時間の計算時間を要したが，TMM では 20 秒程度であった。この点からも本手法の優位性が理解でき る.

\section{4. 結 言}

本研究では，伝達マトリックス法（TMM）の構造解析分野への展開を狙い，回転マトリックスを導入すること で空間内を自由に湾曲するはり構造体を弾塑性解析できるよう定式化した。同理論に基づき作成した解析プログ ラムにより, 直線はりと曲がりはりからなる単純なはり構造体を対象に応力解析を行った。この結果, 集中荷重 と変位の関係において, FEMによる解析結果と TMMによるそれは良く一致したこと, はり断面に生じた応力分 布においても FEM による解析結果によく一致することを確認した. 今後は, さらに複雑な形状を有する機械構 造物に本解析手法を適用していく.

\section{付 録 A}

集中力, 曲げモーメント, トルク, 変位, ねじり角, たわみ角の正の方向は以下の通りである.

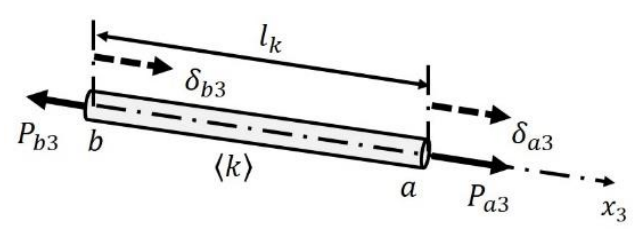

(a) $P_{3}, \delta_{3}$ 


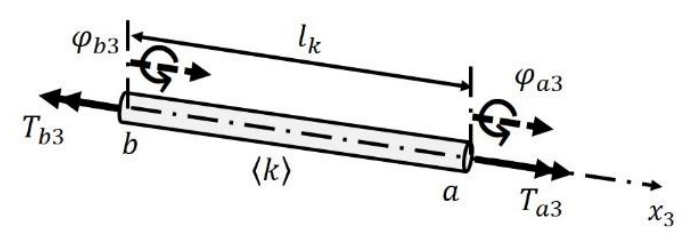

(b) $T_{3}, \varphi_{3}$

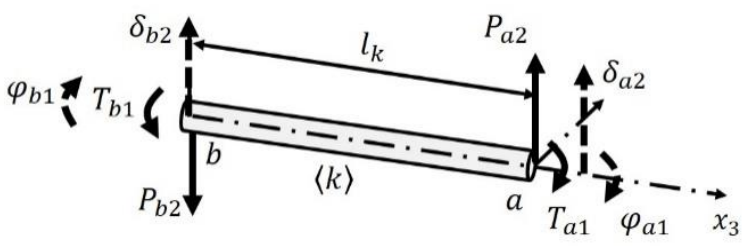

(c) $P_{2}, \delta_{2}, T_{1}, \varphi_{1}$

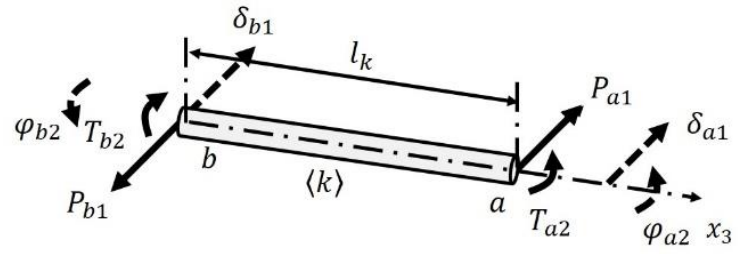

(d) $P_{1}, \delta_{1}, T_{2}, \varphi_{2}$

Fig. A-1 Positive direction of concentrated forces, moments, torques,

displacement, torsional angle and slopes at the edges of the beam element.

\section{付 録 B}

弾性伝達マトリックス ${ }_{\mathcal{F}}^{\langle k\rangle}$ は以下の通りである.

Table B-1The component of elastic transfer matrix.

\begin{tabular}{|c|c|c|c|c|c|c|c|c|c|c|c|}
\hline 1 & 0 & 0 & $\frac{l_{k}^{3}}{6 E_{k} I_{k 2}}$ & 0 & 0 & 0 & $-l_{k}$ & 0 & 0 & $\frac{l_{k}^{2}}{2 E_{k} I_{k 2}}$ & 0 \\
\hline 0 & 1 & 0 & 0 & $\frac{l_{k}^{3}}{6 E_{k} I_{k 1}}$ & 0 & $l_{k}$ & 0 & 0 & $-\frac{l_{k}^{2}}{2 E_{k} I_{k 1}}$ & 0 & 0 \\
\hline 0 & 0 & 1 & 0 & 0 & $-\frac{l_{k}}{E_{k} A_{k}}$ & 0 & 0 & 0 & 0 & 0 & 0 \\
\hline 0 & 0 & 0 & 1 & 0 & 0 & 0 & 0 & 0 & 0 & 0 & 0 \\
\hline 0 & 0 & 0 & 0 & 1 & 0 & 0 & 0 & 0 & 0 & 0 & 0 \\
\hline 0 & 0 & 0 & 0 & 0 & 1 & 0 & 0 & 0 & 0 & 0 & 0 \\
\hline 0 & 0 & 0 & 0 & $\frac{l_{k}^{2}}{2 E_{k} I_{k 1}}$ & 0 & 1 & 0 & 0 & $-\frac{l_{k}}{E_{k} I_{k 1}}$ & 0 & 0 \\
\hline 0 & 0 & 0 & $-\frac{l_{k}^{2}}{2 E_{k} I_{k 2}}$ & 0 & 0 & 0 & 1 & 0 & 0 & $-\frac{l_{k}}{E_{k} I_{k 2}}$ & 0 \\
\hline 0 & 0 & 0 & 0 & 0 & 0 & 0 & 0 & 1 & 0 & 0 & $-\frac{l_{k}}{G_{k} I_{p k}}$ \\
\hline 0 & 0 & 0 & 0 & $-l_{k}$ & 0 & 0 & 0 & 0 & 1 & 0 & 0 \\
\hline 0 & 0 & 0 & $l_{k}$ & 0 & 0 & 0 & 0 & 0 & 0 & 1 & 0 \\
\hline 0 & 0 & 0 & 0 & 0 & 0 & 0 & 0 & 0 & 0 & 0 & 1 \\
\hline
\end{tabular}




\section{References}

Chen, G., Rui, X., Yang, F. and Zhang, J., Study on the natural vibration characteristics of flexible missile with thrust by using Riccati transfer matrix method, Journal of Applied Mechanics, Vol. 83 (2016), pp. 1-8.

Dastjerdi, S. and Abbasi, M., A vibration analysis of a cracked micro-cantilever in an atomic force microscope by using transfer matrix method, Ultramicroscopy, Vol. 196 (2019), pp.33-39.

Geradin, M. and Chen, S. L., An exact model reduction technique for beam structures: combination of transfer and dynamic stiffness matrices, Journal of Sound and Vibration, Vol. 185, No. 3 (1995), pp. 431-440.

Hannezo, E., Prost, J. and Joanny, J.-F., Mechanical instabilities of biological tubes, Physical Review Letters, Vol. 109 (2012), pp. 1-5.

Liu, L. and Lu, N., Variation formulations, instabilities and critical loading of space curved beam, International Journal of Solids and Structures, Vol. 87 (2016), pp.48-60.

Meng, C., Su, M. and Wang, S., An investigation on dynamic characteristics of a gas turbine rotor using an improved transfer matrix method, Journal of Engineering for Gas Turbines and Power, Vol. 135 (2013), pp. 1-8.

Pestel, E. C. and Leckie, F. A., Matrix method in elastomechanics, McGraw-Hill Book Company, Inc., New York (1963).

Provasi, R. and Martins, C. A., A Three-dimensional curved beam element for helical components modeling, Journal of Offshore Mechanics and Arctic Engineering, Vol. 136 (2014), pp. 1-7.

Przemieniecki, J. S., Theory of matrix structural analysis, Dover Publication, Inc., New York (1985).

Zhong, H., Liu, Z., Qin, H. and Liu, Y., Static analysis of thin-walled space frame structures with arbitrary closed cross-sections using transfer matrix method, Thin-Walled Structures, Vol. 123 (2018), pp.255-269. 